\title{
Emissões Otoacústicas Evocadas Transientes em Neonatos a Termo e Pré-Termo na Presença e na Ausência de Sucção
}

Transient evoked otoacoustic emissions in term and pre-term neonates in the presence and absence of suction Emisiones Otoacústicas Evocadas Transitorias en Neonatos a Término Y Prematuros en Presencia Y Ausencia de Succión

\begin{abstract}
RESUMO
Objetivo: Verificar se os ruídos provocados pelo mecanismo de sucção/deglutição interferem nas EOAETs em neonatos a termo e pré-termo. Método: estudo realizado com 40 neonatos (27 nascidos a termo e 13 pré-termo), avaliados com presença de EOAETs, em repouso e em situação de sucção. Resultados: Analisando a ocorrência de EOAETs no momento sem sucção/deglutição em comparação com o momento sucção/deglutição, segundo a freqüência, constatou-se que em 2000 Hz ocorre maior número de falhas durante a sucção. Conclusão: Não houve variação estatisticamente significante entre os resultados obtidos sem sucção e em sucção nutritiva no seio materno, tal achado possibilita que o exame pode ser realizado das duas formas sem prejuízo nos resultados
\end{abstract}

DESCRITORES: Emissões Otoacústicas; Sucção; Neonatos.

\section{ABSTRACT}

Objective: to verify if the sounds caused by the suction / swallowing mechanism interfere with the TEOAE in the term and preterm newborns. Method: a study of 40 newborns (27 full-term and 13 preterm), evaluated with presence of TEOAE, at rest and in suction situation. Results: At the time of suctioning / deglutition, the frequency of suctioning / deglutition was analyzed by frequency; it was found that in $2000 \mathrm{~Hz}$, a greater number of failures occurred during suction Conclusion: There was no statistically significant difference between the results obtained without suction and nutritive suction in the breast.

DESCRIPTORS: Otoacoustic Emissions; Suction; Neonates.

\section{RESUMEN}

Objetivo: Verificar el ruido causado por el mecanismo de interferir al tragar / tragar TEOAE en neonatos para termo y pre-termo. Método: estudio realizado con 40 recién nacidos (27 a término y 13 prematuros), con el apoyo de la presencia de TEOAE, en situación de reutilización y succión. Resultados: Al analizar la aparición de TEOAE, no hay tiempo para succión / deglución en comparación con el momento de succión / deglución, según la frecuencia, se encontró que en 2000 Hz hubo más fallas durante la succión. Conclusión: No hubo variación estadísticamente significativa entre los resultados obtenidos después de la succión y la succión nutricional, y no materna, pudiéndose realizar de dos maneras, sin perjuicio de los resultados.

DESCRIPTORES: Emisiones Otoacústicas; Succión; Neonatos.

RECEBIDO EM: 22/07/2020 APROVADO EM: 08/09/2020

\section{Raquel Amorim Filgueira}

Fonaudiológa, Mestre em Ciências da Saúde pela Faculdade de Medicina do ABC - FMABC.

ORCID: 0000-0001-8454-9196

\section{Roseli Saccardo Sarni}

Médica, Professor Livre-Docente em Pediatria pela Faculdade de Medicina do ABC-FMABC.

ORCID: 0000-0001-5839-0871 


\section{INTRODUÇÃO}

0 primeiro pesquisador com registros referentes à estimulação acústica no meato acústico externo foi Kemp ${ }^{[1]}$ em 1978. As respostas surgiam a partir de 5 milisegundos (ms) após a estimulação, onde foram denominados, a princípio de "eco-coclear", chegando-se posteriormente ao termo Emissões Otoacústicas (EOA).

Neste enquadre situacional, as respostas estavam presentes em indivíduos com limiares dentro da normalidade, não em portadores de surdez neurossensorial. Logo assim, iniciou-se um amplo campo de pesquisas e investigaçôes clínicas diagnósticas em audição humana.

As Emissões Otoacústicas Evocadas (EOA) têm sido exploradas por várias razões. Entre elas, por representar a habilidade da orelha interna em criar as próprias vibrações sonoras, ou seja, a existência da atividade coclear, uma vez que antes acreditava-se que a cóclea fosse passiva. Outra razão foi devido ao desenvolvimento tecnológico das Emissões Otoacústicas Evocadas (EOA), que permitiu seu uso na identificação precoce da deficiência auditiva, Triagem Auditiva Neonatal (TAN), papel fundamental dentro da bateria de testes ${ }^{[2]}$.

Bonfils et al., ${ }^{[3]} \mathrm{em} 1992$ e Morlet et al., ${ }^{[4]}$ em 1993, em estudos com populaçóes mais numerosas, não encontraram diferenças significantes nos níveis de resposta das EOA em função da idade pós-concepcional de prematuros. Chuang et al., ${ }^{[5]} \mathrm{em} 1993$, ao observarem as mudanças do nível de resposta das Emissões Otoacústicas Evocadas Transientes (EOAETs) segundo a idade gestacional, num estudo longitudinal em apenas dois bebês, sugeriram que o processo maturacional não sofre modificações a partir da $38^{\text {a }}$ semana.

Smurzyinski et al., ${ }^{[6]}$ em 1993, comparando grupos de neonatos a termo e pré-termo, observaram que os valores de amplitude geral do grupo pré-termo com risco para deficiência auditiva foram menores que os valores de amplitude geral do grupo a termo. Bassetto ${ }^{[7]}$ em 1998 encontrou diferenças entre o nível de respostas médias das EOAETs entre neonatos de 31 a 36 se- manas e neonatos de 37 a 44 semanas, com respostas superiores para as bandas de freqüências mais altas.

Em um estudo de Pereira et al., ${ }^{[8]}$ realizado em 2007, foi observado a ocorrência de EOAETs em 86,03\% dos neonatos a termo, enquanto nos nascidos pré-termo estava presente apenas em 79,79\%. Assim, notaram que a chance de apresentar ausência de EOAETs aumentava a medida que diminui a idade gestacional.

Embora muitos estudos relatem os fatores que podem interferir na mensuração das EOAETs, não há, no entanto, literatura sobre interferência no exame do ato de sugar e deglutir em neonatos a termo e pré-termo.

A realização do exame em crianças durante a sucção/deglutição é uma prática clínica comum, no entanto pesquisas mostram que os resultados do teste durante a sucção nutritiva $(\mathrm{SN})$ podem diferir dos obtidos em sono natural, sugerindo que a amamentação pode interferir na resposta auditiva ${ }^{\left[{ }^{-17]}\right.}$. No entanto, a rotina clínica tem mostrado que crianças examinadas enquanto sugam não apresentam alterações no resultado do exame.

A realização desta pesquisa justifica-se, pelo fato da sucção/deglutição durante a avaliação das EOAETs ser um recurso útil na prática clínica para tranquilizar a criança, visto que, nessa situação o criança encontra-se em posição confortável, seus movimentos corporais tornam-se reduzidos e a situação de estresse reduzida, facilitando a captação das respostas e torna o exame ainda mais dinâmico. Uma vez que as condições ideais para a mensuração das EOAETs sejam alcançadas, o procedimento poderá ser utilizado com segurança durante a avaliação das EOAETs.

\section{MÉTODO}

Foi realizado um estudo quantitativo, transversal e de intervenção para obtenção de dados na Clínica de Fisioterapia Cardiovascular e Respiratória no Município de Barbalha-CE. Esse estudo foi aprovado pelo Comtê de Ética institucional da UNILEÃO (CAAE:67487517.1.0000.5048).

$\mathrm{O}$ estudo foi constituído por 40 crian- ças (11 do gênero feminino e 29 do gênero masculino), nascidos a termo (27) e pré-termo (13). Foram analisadas 40 orelhas direitas e 40 orelhas esquerdas em um momento sem sucção nutritiva ao seio materno e em outro momento 40 orelhas direitas e 40 orelhas esquerdas no segundo momento com sucção nutritiva ao seio materno.

Os critérios de inclusão na amostra deste estudo foram: crianças que apresentaram presença de EOAETs; idade entre 01 à 03 meses de vida, no momento do exame e que eram amamentadas no seio materno. Os critérios de exclusão:mudança comportamental; obstrução das vias aéreas superiores; choro; otite; presença de sucção com eclosões, apresentação de pressão positiva no processo de amamentação, apresentação de estalos durante a sucção; sinais de estresse durante a sucção, como engasgos, soluços, entre outros; e por fim, os pais ou responsáveis não concordarem com a pesquisa.

Depois de conferidos os critérios de inclusão e obtida a assinatura do Termo de Consentimento Livre e Esclarecido, foram avaliadas em dois momentos e posteriormente divididas em dois grupos distintos:

- Neonatos a termo;

- Neonatos pré-termo.

Ambos os grupos foram avaliados em dois momentos:

- Em repouso, sem sucção;

- Em repouso, durante a sucção: nutritiva no peito ou não nutritiva.

Cada criança, no momento do exame, estava no colo da mãe ou responsável, em posição confortável, com a orelha a ser avaliada livre de qualquer obstrução que pudesse dificultar a introdução da sonda no meato acústico externo.

Não houve preferência na escolha da primeira situação para execução do exame (não sucção ou em sucção), respeitadando-se as condições das crianças em cada momento.

Foi realizada a anamnese para investigar informações sobre os antecedentes familiares de deficiência auditiva, intercorrências durante o período gestacional e condições 
Tabela 1 - Ocorrência de Emissões Otoacústicas Evocadas Transientes (EOATs) sem e com sucção, de toda a amostra segundo a frequência $(n=40)$

$1500 \mathrm{~Hz}$

EOAETS

Presentes

Ausentes

Sem Sucção

$2000 \mathrm{~Hz}$

EOAETS

Presentes

Ausentes

$2500 \mathrm{~Hz}$

EOAETS

Presentes

Ausentes

$3000 \mathrm{~Hz}$
$41 \%$

$59 \%$

\section{Sem Sucção \\ $73 \%$}

$27 \%$

$0,015^{*}$

$38 \%$

$62 \%$

Em Sucção
$53 \%$

$47 \%$

Valor P

Sem Sucção

$88 \%$

$12 \%$

0,65

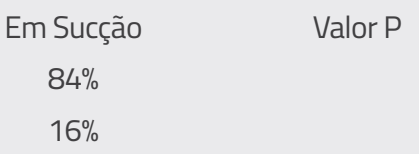

Sem Sucção

$85 \%$

$15 \%$

Em Sucção
$\begin{gathered}83 \% \\ 17 \%\end{gathered}$

0,83

Sem Sucção

$83 \%$

$17 \%$

0,69

Sem Sucção

$78 \%$

$22 \%$

Valor $\mathrm{P}$

Valor P
EOAETS

Presentes

Ausentes

$3500 \mathrm{~Hz}$

EOAETS

Presentes

Ausentes

$4000 \mathrm{~Hz}$

EOAETS

Presentes

Ausentes
Em Sucção

$79 \%$

$21 \%$

Em Sucção

$80 \%$

$20 \%$
0,85

* Relação estatisticamente significante, $p<0,05$ Teste qui-quadrado.

Tabela 2 - Ocorrência de Emissões Otoacústicas Evocadas Transientes (EOAETs) sem e com sucção, segundo a freqüência e dividida entre prétermo e termo. $(\mathrm{n}=40)$

$1500 \mathrm{~Hz}$

EOAETS

A Termo A Termo Sem Sucção Em Sucção

Valor $\mathrm{P}$

Pré-Termo

Pré-Termo

$46 \%$ Em Sucção

Valor $\mathrm{p}$

Presentes

$39 \%$

$35 \%$

$54 \%$

$42 \%$

$65 \%$

$58 \%$
0,55

0,57 do criança, bem como os demais indicadores de risco para deficiência auditiva.

Foi ainda realizada inspeção com a finalidade de verificar a existência de impedimento à testagem das EOAETs, como vérnix, secreções, descamações epiteliais e cerúmen obstruindo parcial ou totalmente o meato acústico externo, com a utilização do otoscópio Welch Allyn 240 A.

A análise das EOAETs foi realizada em local silencioso, as EOAETs foram mensuradas nas frequências de 1500, 2000, 2500, 3000, 3500 e $4000 \mathrm{~Hz}$. A duração do estímulo sonoro foi de aproximadamente 64 segundos. As EOAETs foram consideradas presentes quando houvesse resposta para no mínimo três frequências entre 1500 à $4000 \mathrm{~Hz}$. Os resultados foram impressos e anexados ao protocolo do paciente, com o aparelho Otoread Clínico da marca Interacoustics.

As principais variáveis analisadas foram: variação da amplitude, ruído, e relação sinal/ruído das EOAETs, presença ou ausência das EOAETs e se havia sucção no momento da análise.

Foi aplicado o teste $\mathrm{t}$ de Student para amostras independentes comparando-se as orelhas. Para comparar as frequências de presença/ausência foi adotado o teste "qui-quadrado" para independência entre dois atributos. O nível crítico de significância adotado foi de $5 \%$ de probabilidade.

\section{RESULTADOS}

A análise de presença/ausência de EOAETs por freqüência avaliada, nas situações de sucção e não sucção da amostra apresenta-se na Tabela 1.

A ocorrência de EOAETs, não foram significamente alteradas no momento de sucção, a variação não ultrapassou $5 \%$. Contudo, na frequência de $2000 \mathrm{~Hz}$ houve um aumento no número de ausência de EOAETs, o que não interfere significamente no resultado global da análise, nem no exame prático, haja visto que para alterar o resultado do exame teria que haver ausência em pelo menos 4 frequências.

A análise de presença/ausência de EOAETs por freqüência avaliada, nas situações 


\section{artigo}

Filgueira, R.A.; Sarni, R.S.

Emissões Otoacústicas Evocadas Transientes em Neonatos a Termo e Pré-Termo na Presença e na Ausência de Sucção

\begin{tabular}{|c|c|c|c|c|c|c|}
\hline \multicolumn{7}{|l|}{$2000 \mathrm{~Hz}$} \\
\hline EOAETs & $\begin{array}{c}\text { A Termo } \\
\text { Sem Sucção }\end{array}$ & $\begin{array}{l}\text { A Termo } \\
\text { Em Sucção }\end{array}$ & Valor P & $\begin{array}{l}\text { Pré-Termo } \\
\text { Sem Sucção }\end{array}$ & $\begin{array}{l}\text { Pré-Termo } \\
\text { Em Sucção }\end{array}$ & Valor $p$ \\
\hline Presentes & $70 \%$ & $50 \%$ & & $77 \%$ & $73 \%$ & \\
\hline \multirow[t]{2}{*}{ Ausentes } & $30 \%$ & $50 \%$ & & $23 \%$ & $27 \%$ & \\
\hline & & & $0,0039^{*}$ & & & 0,51 \\
\hline \multicolumn{7}{|l|}{$2500 \mathrm{~Hz}$} \\
\hline EOAETs & $\begin{array}{c}\text { A Termo } \\
\text { Sem Sucção }\end{array}$ & $\begin{array}{l}\text { A Termo } \\
\text { Em Sucção }\end{array}$ & Valor P & $\begin{array}{l}\text { Pré-Termo } \\
\text { Sem Sucção }\end{array}$ & $\begin{array}{l}\text { Pré-Termo } \\
\text { Em Sucção }\end{array}$ & Valor $p$ \\
\hline Presentes & $89 \%$ & $88 \%$ & & $85 \%$ & $73 \%$ & \\
\hline Ausentes & $11 \%$ & $12 \%$ & & $15 \%$ & $27 \%$ & \\
\hline & & & 0,82 & & & $0,03^{*}$ \\
\hline \multicolumn{7}{|l|}{$3000 \mathrm{~Hz}$} \\
\hline EOAETs & $\begin{array}{c}\text { A Termo } \\
\text { Sem Sucção }\end{array}$ & $\begin{array}{l}\text { A Termo } \\
\text { Em Sucção }\end{array}$ & Valor P & $\begin{array}{l}\text { Pré-Termo } \\
\text { Sem Sucção }\end{array}$ & $\begin{array}{l}\text { Pré-Termo } \\
\text { Em Sucção }\end{array}$ & Valor $p$ \\
\hline Presentes & $83 \%$ & $85 \%$ & & $88 \%$ & $77 \%$ & \\
\hline Ausentes & $17 \%$ & $15 \%$ & & $12 \%$ & $23 \%$ & \\
\hline & & & 0,7 & & & $0,04^{*}$ \\
\hline \multicolumn{7}{|l|}{$3500 \mathrm{HZ}$} \\
\hline EOAETs & $\begin{array}{c}\text { A Termo } \\
\text { Sem Sucção }\end{array}$ & $\begin{array}{c}\text { A Termo } \\
\text { Em Sucção }\end{array}$ & Valor P & $\begin{array}{l}\text { Pré-Termo } \\
\text { Sem Sucção }\end{array}$ & $\begin{array}{l}\text { Pré-Termo } \\
\text { Em Sucção }\end{array}$ & Valor $p$ \\
\hline Presentes & $81 \%$ & $78 \%$ & & $81 \%$ & $80 \%$ & \\
\hline Ausentes & $19 \%$ & $22 \%$ & & $19 \%$ & $20 \%$ & \\
\hline & & & 0,6 & & & 0,86 \\
\hline \multicolumn{7}{|l|}{$4000 \mathrm{HZ}$} \\
\hline EOAETs & $\begin{array}{c}\text { A Termo } \\
\text { Sem Sucção }\end{array}$ & $\begin{array}{l}\text { A Termo } \\
\text { Em Sucção }\end{array}$ & Valor P & $\begin{array}{l}\text { Pré-Termo } \\
\text { Sem Sucção }\end{array}$ & $\begin{array}{l}\text { Pré-Termo } \\
\text { Em Sucção }\end{array}$ & Valor $p$ \\
\hline Presentes & $74 \%$ & $80 \%$ & & $85 \%$ & $81 \%$ & \\
\hline Ausentes & $26 \%$ & $20 \%$ & 0,31 & $15 \%$ & $19 \%$ & 0,45 \\
\hline
\end{tabular}

Tabela 3 - Análise das Emissões Otoacústicas Evocadas Transientes (EOAETs) em neonatos a termo, segundo a freqüência, sem e com sucção no peito.

$\begin{array}{lcccc}\text { Orelha } & \text { Variáveis } & \begin{array}{c}\text { Média sem sucção } \\ \text { de neonatos a ter- } \\ \text { mo (Desvio Padrão) }\end{array} & \begin{array}{c}\text { Média durante a sucção } \\ \text { de neonatos a termo } \\ \text { (Desvio Padrão) }\end{array} & \text { Valor de p } \\ \text { 1500HZ } & \text { Amplitude } & 6,59(4,07) & 8,22(3,72) & 0,13 \\ \text { Direita } & \text { Ruído } & 3,29(4,91) & 4,77(4,26) & 0,24 \\ & \text { Relação S/R } & 3,18(3,88) & 3,33(3,74) & 0,88 \\ \text { Esquerda } & \text { Amplitude } & 8,18(5,74) & 7,88(7,17) & 0,87 \\ & \text { Ruído } & 6,22(6,16) & 7,22(5,93) & 0,5 \\ 2000 \mathrm{~Hz} & \text { Relação S/R } & 2,7(4,23) & 1,11(4,73) & 0,2 \\ & & & & 0,7\end{array}$

de sucção e não sucção e divida por não prematuridade ou prematuridade apresenta-se na Tabela 2.

A correlação entre a situação de não sucção e sucção no peito, para neonatos a termo mediante as variáveis analisadas, está apresentada na Tabela 3.

A correlação entre a situação de não sucção e sucção no peito, para neonatos pré-termo mediante as variáveis analisadas, está apresentada na Tabela 4.

\section{DISCUSSÃO}

Existem vantagens na utilização das EOA como teste clínico, entre elas estão a maneira simples, não invasiva e rápida, de se captar EOA no meato acústico externo, essa última explica o porquê são úteis na triagem da função coclear em neonatos.

Analisando a ocorrência de EOAETs no momento sem sucção/deglutição em comparação com o momento sucção/ deglutição, segundo a freqüência, constatou-se que em $2000 \mathrm{~Hz}$ houve maior número de falhas durante a sucção. Almeida et al., ${ }^{[16]}$ realizando um estudo semelhante em 2004, perceberam que as bandas 1 e 2 (freqüências baixas) eram as mais prejudicadas durante a amamentação, e que a medida que as freqüências aumentavam, diminuía-se o prejuízo. Tais achados são concordantes com os observados em outras pesquisas ${ }^{[9-18]}$.

Comparando-se os grupos de neonatos a termo com o grupo de neonatos pré-termo, a ocorrência de EOAETs no momento sem sucção/deglutição em comparação com o momento sucção/deglutição, segundo a freqüência, notou-se que em $2000 \mathrm{~Hz}$ ocorre maior número de falhas durante a sucção no grupo de neonatos a termo corroborando com o primeiro achado. No entanto, no grupo de neonatos pré-termo notou-se que em $2500 \mathrm{~Hz}$ e $3000 \mathrm{~Hz}$ ocorrem maior número de falhas durante a sucção.

Kei et al., ${ }^{[19]}$ observaram que o neonato em sucção ou em respiração ruidosa eram responsáveis pelo fracasso nos testes de EOAETs em 11,27\% das avaliações. As freqüências mais baixas, durante a amamentação, são as mais prejudicadas na avaliação, e 


\begin{tabular}{|c|c|c|c|c|}
\hline \multirow[t]{3}{*}{ Direita } & Ruído & $-3,44(5,15)$ & $-1,92(4,78)$ & 0,26 \\
\hline & Relação S/R & $6,96(5,34)$ & $5,11(5,06)$ & 0,19 \\
\hline & Amplitude & $3,37(3,80)$ & $3,66(4,16)$ & 0,80 \\
\hline \multirow[t]{2}{*}{ Esquerda } & Ruído & $-2,85(4,61)$ & $-1,25(5,79)$ & 0,27 \\
\hline & Relação S/R & $5,66(4,42)$ & $5,37(5,10)$ & 0,82 \\
\hline \multicolumn{5}{|l|}{$2500 \mathrm{~Hz}$} \\
\hline & Amplitude & $-1,18(4,02)$ & $-1,25(4,10)$ & 0,95 \\
\hline \multirow[t]{3}{*}{ Direita } & Ruído & $-11,29(3,77)$ & $-9,77(3,49)$ & 0,13 \\
\hline & Relação S/R & $10,07(4,49)$ & $5,11(3,45)$ & $0,0005^{*}$ \\
\hline & Amplitude & $-0,88(5,22)$ & $-0,11(5,15)$ & 0,59 \\
\hline \multirow[t]{2}{*}{ Esquerda } & Ruído & $-9,74(7,04)$ & $-9,5(4,79)$ & 0,93 \\
\hline & Relação S/R & $9,11(4,85)$ & $8,71(4,23)$ & 0,75 \\
\hline \multicolumn{5}{|l|}{$3000 \mathrm{~Hz}$} \\
\hline & Amplitude & $-2,25(5,59)$ & $-3,5(5,70)$ & 0,44 \\
\hline \multirow[t]{3}{*}{ Direita } & Ruído & $-13,81(2,98)$ & $-13,74(3,20)$ & 0,94 \\
\hline & Relação S/R & $10,67(6,26)$ & $10,29(6,19)$ & 0,83 \\
\hline & Amplitude & $-3,85(4,70)$ & $-2,92(4,08)$ & 0,45 \\
\hline \multirow[t]{2}{*}{ Esquerda } & Ruído & $-12,29(7,50)$ & $-11,18(9,36)$ & 0,63 \\
\hline & Relação S/R & $8,37(5,79)$ & $10,45(3,63)$ & 0,12 \\
\hline \multicolumn{5}{|l|}{$3500 \mathrm{~Hz}$} \\
\hline & Amplitude & $-1,14(5,88)$ & $-1,03(6,07)$ & 0,95 \\
\hline \multirow[t]{3}{*}{ Direita } & Ruído & $-10,55(3,60)$ & $-10,25(3,66)$ & 0,77 \\
\hline & Relação S/R & $8,81(6,67)$ & $9,18(5,66)$ & 0,83 \\
\hline & Amplitude & $-2,03(6,50)$ & $-2,29(5,96)$ & 0,88 \\
\hline \multirow[t]{2}{*}{ Esquerda } & Ruído & $-9,7(7,01)$ & $-10,77(4,81)$ & 0,53 \\
\hline & Relação S/R & $7,85(5,47)$ & $9,37(8,11)$ & 0,43 \\
\hline \multicolumn{5}{|l|}{$4000 \mathrm{~Hz}$} \\
\hline & Amplitude & $-0,88(6,74)$ & $-0,85(6,54)$ & 0,98 \\
\hline \multirow[t]{3}{*}{ Direita } & Ruído & $-9(4,90)$ & $-7,74(5,41)$ & 0,38 \\
\hline & Relação S/R & $8,37(6,02)$ & $7,66(5,54)$ & 0,66 \\
\hline & Amplitude & $-1,66(5,82)$ & $-1,12(5,80)$ & 0,73 \\
\hline \multirow[t]{2}{*}{ Esquerda } & Ruído & $-7,85(5,86)$ & $-7,41(6,33)$ & 0,79 \\
\hline & Relação S/R & $7,18(4,96)$ & $7,37(4,63)$ & 0,89 \\
\hline
\end{tabular}

Tabela 4 - Análise das Emissões Otoacústicas Evocadas Transientes (EOAETs) em neonatos pré-termo, segundo a freqüência, sem e com sucção no peito.

\begin{tabular}{|c|c|c|c|}
\hline Orelha & Variáveis & $\begin{array}{l}\text { Média sem sucção } \\
\text { de neonatos } \\
\text { pré-termo (Desvio } \\
\text { Padrão) }\end{array}$ & $\begin{array}{l}\text { Média durante a sucção } \\
\text { de neonatos pré-termo } \\
\text { (Desvio Padrão) }\end{array}$ \\
\hline
\end{tabular}

$1500 \mathrm{HZ}$
$7,93(5,91)$

$9(5,11)$ quanto mais agudas, menos influência têm sobre a avaliação.

Quando analisamos a variável ruído, notamos que em todas as freqüências não houve diferenças estatisticamente relevantes quanto a intensidade durante a avaliação das EOAETs quando estava em sucção tanto na orelha esquerda quanto na orelha direita nos neonatos nascidos a termo ( $\mathrm{Ta}$ bela 3). Nesse mesmo grupo, no entanto, em $2500 \mathrm{~Hz}$ houve interferência significativa na relação sinal/ruído, que foi menor na orelha direita, durante a sucção. Já no grupo de neonatos pré-termo foi percebido que a relação sinal/ruído durante a sucção/deglutição, apesar de se manter muito próxima do valor obtido no momento sem sucção, diminuiu na maioria das freqüências e em ambos os ouvidos.

Analisando essa mesma variável, Almeida et al.. ${ }^{[16]}$ notaram um número elevado de exames alterados durante a amamentação, tanto para a relação sinal/ruído quanto na reprodutibilidade sugerindo que há perda na qualidade dos exames realizados nessa condição. É provável que essa faixa de frequência de $2500-3000 \mathrm{~Hz}$ seja uma faixa de alta sensibilidade do teste em que pequenas interferências geram alterações relevantes dos resultados.

Em outros estudos ${ }^{[19-24]}$ também foi relatada uma maior amplitude de resposta das EOAETs na orelha direita, ademais foi percebido que eram mais relevantes no gênero feminino. Desse modo, os achados deste estudo coincidem com a literatura para as variáveis analisadas.

Outros autores, apesar de não terem pesquisado as EOAETs durante a amamentação, também relataram que o ruído contamina a resposta das EOAETs, além de prejudicar a relação sinal/ruído e a reprodutibilidade, tornando as respostas diminuídas para as freqüências mais baixas ${ }^{[9-17]}$.

Ao se medir com microfone o som da deglutição no meato acústico externo e na cricofaringe observou-se que o som se concentrava entre 400 e $600 \mathrm{~Hz}$ com pico em $1384 \mathrm{~Hz}$, em estudos sobre a concentração da energia acústica durante a deglutiçãoo ${ }^{[25,26]}$. Esse fato não pode ser observado nos nossos achados, uma vez que as 


\begin{tabular}{|c|c|c|c|c|}
\hline \multirow[t]{3}{*}{ Direita } & Ruido & $7,92(7,94)$ & $5(7,12)$ & 0,44 \\
\hline & Relação S/R & $2,69(5,05)$ & $3,92(4,97)$ & 0,49 \\
\hline & Amplitude & $8(3,13)$ & $9,15(4,11)$ & 0,44 \\
\hline \multirow[t]{2}{*}{ Esquerda } & Ruido & $3(6,31)$ & $5,61(6,21)$ & 0,3 \\
\hline & Relação S/R & $4,92(5,54)$ & $3,38(4,87)$ & 0,46 \\
\hline \multicolumn{5}{|l|}{$2000 \mathrm{~Hz}$} \\
\hline & Amplitude & $3,61(4,14)$ & $4,07(4,20)$ & 0,8 \\
\hline \multirow[t]{3}{*}{ Direita } & Ruido & $-2,77(5,73)$ & $-1,23(5,65)$ & 0,5 \\
\hline & Relação S/R & $6,46(3,71)$ & $5,46(4,07)$ & 0,52 \\
\hline & Amplitude & $5,23(4,24)$ & $4,92(4,42)$ & 0,86 \\
\hline \multirow[t]{2}{*}{ Esquerda } & Ruido & $-3,61(5,96)$ & $-1,85(4,35)$ & 0,4 \\
\hline & Relação S/R & $8,84(6,03)$ & $6,85(6,76)$ & 0,45 \\
\hline \multicolumn{5}{|l|}{$2500 \mathrm{~Hz}$} \\
\hline & Amplitude & $-2,6(4,30)$ & $-2,3(4,14)$ & 0,86 \\
\hline \multirow[t]{3}{*}{ Direita } & Ruido & $-9,62(7,45)$ & $-9,46(6,40)$ & 0,96 \\
\hline & Relação S/R & $8,38(3,22)$ & $7,07(5,28)$ & 0,45 \\
\hline & Amplitude & $-1,23(4,10)$ & $-2,07(5,52)$ & 0,67 \\
\hline \multirow[t]{2}{*}{ Esquerda } & Ruido & $-11,31(5,66)$ & $-10,69(5,07)$ & 0,78 \\
\hline & Relação S/R & $9,92(5,53)$ & $8,38(6,51)$ & 0,53 \\
\hline \multicolumn{5}{|l|}{$3000 \mathrm{~Hz}$} \\
\hline & Amplitude & $-2,46(3,91)$ & $-3,77(3,87)$ & 0,42 \\
\hline \multirow[t]{3}{*}{ Direita } & Ruido & $-12,23(7,69)$ & $-11(9,01)$ & 0,71 \\
\hline & Relação S/R & $10,15(4,32)$ & $8,92(5,18)$ & 0,53 \\
\hline & Amplitude & $-2,15(6,16)$ & $-2,39(6,09)$ & 0,93 \\
\hline \multirow[t]{2}{*}{ Esquerda } & Ruido & $-11,85(10,16)$ & $-11,38(8,87)$ & 0,91 \\
\hline & Relação S/R & $12,53(6,98)$ & $11,38(6,19)$ & 0,67 \\
\hline \multicolumn{5}{|l|}{$3500 \mathrm{~Hz}$} \\
\hline & Amplitude & $-1(6,99)$ & $-1,2(7,82)$ & 0,93 \\
\hline \multirow[t]{3}{*}{ Direita } & Ruido & $-10,92(8,75)$ & $-11,23(4,93)$ & 0,92 \\
\hline & Relação S/R & $11,53(6,54)$ & $10,15(6,96)$ & 0,61 \\
\hline & Amplitude & $-0,15(6,59)$ & $-1,0(7,17)$ & 0,76 \\
\hline \multirow[t]{2}{*}{ Esquerda } & Ruido & $10,23(6,70)$ & $-11,07(3,68)$ & 0,72 \\
\hline & Relação S/R & $11,23(5,15)$ & $10,23(6,04)$ & 0,66 \\
\hline \multicolumn{5}{|l|}{$4000 \mathrm{~Hz}$} \\
\hline & Amplitude & $-1,84(6,99)$ & $-1,61(7,82)$ & 0,94 \\
\hline \multirow[t]{3}{*}{ Direita } & Ruido & $-10,38(8,75)$ & $-9,69(4,93)$ & 0,7 \\
\hline & Relação S/R & $8,53(6,54)$ & $7,85(6,96)$ & 0,77 \\
\hline & Amplitude & $-1(6,59)$ & $-2(7,17)$ & 0,6 \\
\hline \multirow[t]{2}{*}{ Esquerda } & Ruido & $-9,38(6,69)$ & $-9,39(3,68)$ & 0,99 \\
\hline & Relação S/R & $7,76(5,15)$ & $6,46(6,04)$ & 0,31 \\
\hline
\end{tabular}

freqüências analisadas em nossas pesquisa eram a partir de $1500 \mathrm{~Hz}$ e iam até $4000 \mathrm{~Hz}$.

Em outro estudo, Gorga et al., ${ }^{[27]}$ observaram que os níveis de respostas das EOAPD eram maiores em 1500 e 2000 $\mathrm{Hz}$, comparadas com 3000 e $4000 \mathrm{~Hz}$. No entanto, ao passo que as freqüências aumentavam, os níveis de ruído diminuíam e resultavam em uma relação sinal/ ruído mais favorável em 3000 e $4000 \mathrm{~Hz}$. Assim, excetuando-se a atividade corporal e o choro dos neonatos, o estado teve pouca influenciou os resultados das EOAPD.

$\mathrm{O}$ ambiente em que é realizado o exame não provocou influência na aferição das EOAPD, sugerindo que a fonte primária do ruído é interna ao neonato (respiração, movimento, etc.). Assim, sugere que os sons ruidosos tem origem interna do neonato.

A dificuldade de registro das EOAPD nas frequiências mais baixas se deve ao fato de que à fonte primária do ruído é a respiração e os movimentos do recém-nascido, cujo espectro de freqüências se manifestam principalmente nos sons graves ${ }^{[28]}$.

Por esse motivo, ao se mensurar as emissões otoacústicas, o ruído está sempre presente, mas é percebido mais intensamente na região de freqüências próxima 1500 $\mathrm{Hz}$, podendo vir raramente do ambiente ou mais frequentemente das atividades fisiológicas, como a sucção ou deglutição, do próprio paciente ${ }^{[29]}$.

\section{LIMITAÇÕES DO ESTUDO}

O estudo usa os parâmetros de frequência padronizados do aparelho de medida (1500 - $4000 \mathrm{~Hz}$ ), é possível que outros aparelhos com outros padrões, ou seja, que apresentaram frequências inferiores a $1500 \mathrm{~Hz}$ ou superiores a $4000 \mathrm{~Hz}$ tenham resultados diferentes do apresentado nesse estudo.

$\mathrm{Na}$ anamnese foi pesquisado para indicadores de risco para deficiência auditiva, contudo poucos neonatos tinham presente algum indicador. Assim, é possível que analisando uma amostra única e maior de neonatos com indicadores de riscos presente, seja encontrado algum um achado significativo ou alguma interferência não relata no presente estudo. 


\section{CONCLUSÃO}

O estudo avaliou se os ruídos produzidos durante a sucção ou a deglutição interferiam nas EOAETs de neonatos a termo e pré-termo. Constatamos que as alterações observadas não apresentaram diferença nas frequências mais altas e não apresentaram diferença estatisticamente significante nas baixas frequências para gerar alteração nos resultados finais dos exames e, consequentemente, no diagnóstico.

Desse modo, a avaliação das EOA-
ETs pode ser executada em neonatos durante a sucção, já que os critérios mínimos para validar o exame são atingidos e as alterações produzidas com esta estratégia não prejudicam as respostas ao ponto de evidenciar resultados falso/ positivos.

\section{REFERÊNCIAS}

1. Kemp DT. Stimulated acoustic emissions from within the human auditory system. J Acoust Soc Am.1978;64(5):1386-91.

2. Lonsbury-Martin BL, Martin GK, Telischi FF. Emissões otoacústicas na prática clínica. "In": Musiek FE, Rintelmann WF. Perspectivas atuais em avaliação auditiva. São Paulo: Manole; 2001. p. 163-92.

3. Bonfils, P. et al. Spontaneous and evoked otoacoustic emissions in pré-term neonates. Laryngoscope, v. 102, p. 182-86, 1992.

4. Morlet, T. et al. Functional maturation of cochlear active mechanisms and of the medial olivocochlear system in humans. Acta Otolaryngol (Stockh), v. 113, p. 271-8, 1993.

5. Chuang, S.W.; Gerber, S.E.; Thornton, A.R.D. Evoked otoacoustic emissions in pre-term infants. Int J Pediatr Otorhinolaryngol., v. 26, p. 39-45, 1993.

6. Smurzynski, J. et al. Distortion-product and click-evoked otoacoustic emissions of preterm and full-term infantis. Ear hear., v. 14, p. 258-74, 1993.

7. Basseto, M.C.A. Emissões otoacústicas evocadas transientes: estudo da amplitude de resposta em recém-nascidos a termo e pré-termo. 1998. Tese - Universidade Federal de São Paulo. São Paulo, 1998.

8. Pereira, P.K.S. et al. Programa de triagem auditiva neonatal: associação entre perda auditiva e fatores de risco. Pró-Fono, v. 19, p. 267-78.

9. Davis, H. Audiometry: puretone and simple speech tests. "In": Davis $\mathrm{H}$, Silverman SR. Hearing and deafness. $3^{\mathrm{a}}$ ed. New York: Holt, Rinehart \& Winston; 1970.

10. Hatzopoulos S, Mazzoli M, Martini A. Identification of Hearing Loss Using TEOAE Descriptors: Theorical Foundations and preliminary results. Audiology. 1995;34:248-59

11. Marco J, Morant A, Caballero J, Ortells I, Paredes C, Brines J. Distortion Product Otoacoustic Emissions in healthy newborns: Normative Data. Acta Otolaryngol. 1995;115:187-89.

12. Widen JE. Evoked Otoacoustic Emissions in Children. "In": Otoacoustic Emissions Clinical Aplication. New York: Thieme; 1997.

13. Norton S, Gorga M, Widen J, Vohr B, Folsom R, Sininger Y. et al. Identification of neonatal hearing impairment: evoluation of transient evoked otoacustic emission, distorcion product otoacustic emission and auditory brainstem response test performance. Ear Hear. 2000;21(5):508-28.

14. Quiñónez RE. Distortion-product otoacoustic emissions in neonates: frequency ratio (F2/F1) and a stimulus level differences (L1/ L2). Acta Otolaryngol (stockh). 1999;119:431-36.

15. Ribeiro FM. Programa de Triagem Auditiva Neonatal. "In": Her- nandez AM, Marchesan I. Atuação Fonoaudiológica no Ambiente Hospitalar. Rio de Janeiro: Revinter; 2001. p.152-55.

16. Almeida VF, Oliveira CACP, Venosa AR, Zanchetta S. Emissões Otoacústicas Evocadas Transitórias em Recém-nascidos a Termo Durante Amamentação. Arq Otorrinolaringol. 2004;8(2):120-26.

17. Precthl HFR. The behavioral states of newborn infant (a review). Brain Dev. 1974; 76:185-212.

18. Joint Committee on Infant Hearing. Year 2007 position statement: principles and guidelines for early hearing detection and intervention programs. Pediatrics, v. 120, n. 4, p. 898-921, 2007.

19. Kei J, Macpherson B, Smyth V, Lathammm S, Loscher J. Transient Evoked Otoacoustic Emissions in Infants: Effects of Gender, Ear Asymmetry and Activity Status. Audiology. 1997;36:61-71.

20. Basseto MCA. Triagem auditiva em berçário. "In": Bassetto MCA, Brock R, Wajnsztejn R. Neonatologia - Um convite à atuação fonoaudiológica. São Paulo: Lovise. 1998. p.289-93.

21. Basseto MCA, Chiari BM, Azevedo MF. Emissões otoacústicas evocadas transientes (EOAET): amplitude da resposta em recém-nascidos a termo e pré-termo. Rev Bras Otorrinolaringol. 2003;69:84-92.

22. Durante A, Carvallo R, Costa F, Soares J. Características das emissões otoacústicas por transientes em programa de triagem auditiva neonatal. Pró-fono. 2005;17(2):133-39.

23. Saitoh Y. et al. Transient Evoked Otoacoustic Emissions in Newborn Infants: Effects of Ear Asymmetry, Gender, and Age. J Otolaryngol. 2006;35:133-8.

24. Berninger E. Characteristics of normal newborn transient-evoked otoacoustic emissions: ear asymmetries and sex effects. Int J Audiol. 2007;46:661-9.

25. Hamlet SL, Nelson RJ, Patterson RL. Interpreting the sounds of swallowing: Fluid flow through the cricopharyngeus. Ann Otolrhinolaryngol. 1990;99:749-52.

26. Takahashi K, Groher ME, Michi K. Methodology for Detecting Swallowing Sounds. Dysphagia. 1994;9:54-62.

27. Gorga MP. et al. Identification of neonatal hearing impairment: distortion product otoacoustic emissions during the perinatal period. Ear Hear. 2000;21(5):400-24.

28. Cerruti VQ. Estudo das emissões otoacústicas evocadas em neonatos: transientes e produto de distorção [Tese]. São Paulo (SP): Universidade de São Paulo; 2000.

29. Hall J. Distortion Product and Transient Evoked OAEs: Effect of Auditory Dysfunction. "In": Hall J. Handbook of Otoacoustic Emissions. San Diego: Singular; 2000. 